\title{
Assessment of Self-medication Practices During COVID-19 Pandemic in Hyderabad and Karachi, Pakistan
}

\author{
Mudassar Iqbal Arain1, Saira Shahnaz², Ramesha Anwar, and Khurram \\ Anwar ${ }^{4}$ \\ ${ }^{1}$ Department of Pharmacy Practice, Faculty of Pharmacy, University of Sindh, Jamshoro, Pakistan \\ ${ }^{2}$ Department of Pharmacy Practice, Faculty of Pharmacy, Nazeer Hussain University, Karachi, \\ Pakistan \\ ${ }^{3}$ Department of Pharmacy Practice, Faculty of Pharmacy, University of Karachi, Karachi, Pakistan \\ ${ }^{4}$ Isra Dental College, Hyderabad, Pakistan
}

ORCID:

Mudassar lqbal Arain: https://orcid.org/0000-0002-1797-9927

\section{Abstract}

Background: Lack of appropriate treatment for COVID-19 infection led the general

Corresponding Author: Mudassar Iqbal Arain; email: mudassarpk@live.com

Received 23 July 2021

Accepted 05 September 2021

Published 30 September 2021

Production and Hosting by Knowledge E

(c) Mudassar Iqbal Arain et al.. This article is

distributed under the terms of the Creative Commons

Attribution License, which permits unrestricted use and redistribution provided that the original author and source are credited.

Editor-in-Chief:

Prof. Mohammad A. M. Ibnouf population of Pakistan toward self-medication and symptomatic treatment; almost $80 \%$ of the population collected medications for future use during pandemic. Thus, the current study aimed to assess the use of medication as symptomatic treatment preventive strategy.

Methods: This descriptive cross-sectional study was conducted on a local population of Hyderabad and Karachi, Sindh, Pakistan. The study duration was six months (AprilSeptember 2020). A total of 698 responders were selected via random sampling method. The number of participants were recruited based on $95 \%$ confidence interval with $5 \%$ margin error. Data were transferred into analysis sheet descriptively.

Results: Most participants responded to the use of different over-the-counter (OTC) products for headache. The use of antibiotics with prescription due to allergic conditions, cough, respiratory tract infections including sore throat, and urinary tract infections was also found among the majority. Few respondents had self-medication practice with sedatives due to difficulty in falling asleep, and $9.5 \%$ had self-medication practice due to pain. About $20.8 \%$ of the population agreed that lockdown was a contributing factor in the self-medication practice.

Conclusion: Pharmacists and healthcare professionals are advised to counsel the general public regarding the use of medication. A close collaboration is required at this stage to fight against COVID-19 and preventing the situation from worsening.

Keywords: self-medication, covid-19, Hyderabad, Karachi, Pakistan

\section{G OPEN ACCESS}




\section{Introduction}

The World Health Organization (WHO) defines self-medication (SM) as utilization of a medication without being prescribed by a healthcare professional to target symptoms that are self-recognized [1]. SM includes usage of medication through direct purchase from pharmacies, reusing previously prescribed medicines, or buying overthe-counter (OTC) medications from medical stores/pharmacies [2]. The most commonly self-prescribed medications are analgesics, antipyretics, sedative drugs, certain common antibiotics, supplements, herbal medicines, and homeopathic remedies. COVID-19 broke in as an infection in the late 2019, since then 30,905,162 confirmed cases were reported till the mid of 2020 [3, 4]. The WHO declared this situation as pandemic in the beginning of 2020. The pandemic and the fear of getting infected increased with the number of cases. COVID-19 has influenced the entire world with the confusion to preventive measures and no available treatment [5]. Cases of SM increased due to lack of appropriate guidelines to establish safety and treatment [6]. More number of people started SM practice to treat symptoms of infections such as cold, flu, and to strengthen their immunity in 2020 regardless of their knowledge, level of education, and socioeconomic status [7]. The literature supports high levels of SMs among underdeveloped countries where the healthcare systems are costly and difficult to approach. Despite the fact that WHO stresses on rational prescribing practices and avoiding OTC medication among general population, this practice is constantly rising. SM may cause resistance to microorganisms and serious health risks with adverse drugs reactions, prolonging the morbidities [8]. Compared to other developed countries, the doctors-to-patients ratio in Pakistan was low. Researchers and healthcare professionals are continuously searching for solution to combat the symptoms of COVID-19 [9]. Most countries in the world went into a lockdown, confining general public to their homes, so people could rely only on social media for updates and information related to the pandemic [1012]. According to a recent report in March 2020, a 10-fold increase in the number of cases was noted only in the span of three months. The total deaths reported were six times more than the previous record [12]. The lack of a recognized treatment for the infection led people toward SM and symptomatic treatment, almost $80 \%$ of the population collected medication for future use during the pandemic. Thus, the current study aimed to assess the use of medication as symptomatic treatment preventive strategy. 


\section{Materials and Methods}

A descriptive cross-sectional study was conducted among the local population of Hyderabad and Karachi, Sindh, Pakistan. The duration of study was six months (AprilSeptember 2020). A total of 698 responders were selected from various retail pharmacies via random sampling method. Retail pharmacies were selected based on patients' flow. The number of participants were recruited based on 95\% confidence interval with $5 \%$ margin error. Patients aged $>18$ years and visiting one of the selected retail pharmacy were included. Verbal consent was also taken from the responders before filling the questionnaire. The questionnaire was divided into three parts: sociodemographic information; SM practices; and knowledge regarding COVID-19. The questionnaire was validated among 50 participants and necessary changes were made. Data were transferred descriptively into the analysis sheet.

\section{Results}

Of the 698 respondents, $56.2 \%$ were male while $43.8 \%$ were female. Based on their age, patients were divided into three categories: $19.3 \%$ were in the group of 18-38 years, $43.4 \%$ in $39-59$ years, and $37.3 \%$ in $>60$ years. Moreover, about $43.7 \%$ of the responders were illiterate while $56.3 \%$ were educated (Table 1 ). The responders were also questioned about their current jobs $-28.2 \%$ were unemployed, $53.5 \%$ had a private job, and $18.3 \%$ had a government job.

TABLE 1: Demographic information.

\begin{tabular}{l|l|l}
\hline Variable & Frequency & Percentage \\
Gender & 393 & $56.2 \%$ \\
Male & 305 & $43.8 \%$ \\
\hline Female & & \\
\hline Age (yr) & 134 & $19.3 \%$ \\
\hline $18-38$ & 302 & $43.4 \%$ \\
\hline $39-59$ & 260 & $37.3 \%$ \\
\hline$\geq 60$ & & \\
\hline Education & 304 & $43.6 \%$ \\
\hline Illiterate & 394 & $56.3 \%$ \\
\hline Literate & & \\
\hline Job status & 197 & $28.2 \%$ \\
\hline Unemployed & 373 & $53.5 \%$ \\
\hline Private job & 127 & $18.3 \%$
\end{tabular}


The main objective of the study was to assess the prevalence of SM practice and the reason thereof. Majority of the participants responded to the use of different OTC products $-23.3 \%$ for the headache and seasonal cough and cold symptoms. However, the use of antibiotics with prescription due to allergic conditions, cough and respiratory tract infections including sore throat, and urinary tract infections was also found among the majority. Few respondents practiced SM with sedatives due to difficulty in falling asleep, while $9.5 \%$ had it due to pain (Table 2 ).

TABLE 2: Reasons of self-medication.

Reason
OTC products for common
illness
Use of antibiotics for
infective symptoms
Others

\begin{tabular}{l|l} 
Headache & 163 \\
\hline Cold & 135 \\
Fever & 107 \\
\hline Allergy & 25 \\
\hline Cough & 45 \\
\hline Respiratory infection & 93 \\
\hline Urinary tract infection & 42 \\
\hline Sleeping problem & 18 \\
\hline Body ache/ muscular pain & 66
\end{tabular}

Frequency
163
135
107
25
45
93
42
18
66

\begin{tabular}{|l|l|}
\hline Percentage & $P$-value \\
\hline $23.3 \%$ & 0.004 \\
\hline $19.4 \%$ & 0.005 \\
$15.4 \%$ & 0.034 \\
\hline $3.7 \%$ & 0.013 \\
\hline $6.5 \%$ & 0.001 \\
\hline $13.4 \%$ & 0.005 \\
\hline $6.1 \%$ & 0.001 \\
\hline $2.6 \%$ & 0.021 \\
\hline $9.5 \%$ & $<0.001$ \\
\hline
\end{tabular}

Factors involved in the use of SM during the pandemic were assessed and respondents were asked about the basic reasons behind the off-prescription use of medication: majority of them were afraid of getting infected in case of going out and seeking medical advice, 30.5\% were afraid of getting the COVID-19 infection. During the peak of pandemic, a large number of countries observed lockdown confining people to their homes for months, this is considered as one of the contributing factors in the rising SM practice; about $20.8 \%$ of the respondents agreed to this, $5.5 \%$ stated the long waiting hours at the clinics as their reason for practicing SM, while $12.6 \%$ practiced SM based on their previous knowledge and experience with the disease (Table 3).

TABLE 3: Factors of self-medication in context of COVID-19.

Factors
Due to minor problem
Lockdown
Busy schedules of doctors
Fear to get COVID-19
Previous knowledge regarding the problem
High fees
Time wastage

Frequency
88
145
68
213
88
58
38

Percentage
$12.6 \%$
$20.8 \%$
$9.7 \%$
$30.5 \%$
$12.6 \%$
$8.4 \%$
$5.5 \%$




\section{Discussion}

SM practice is a major issue that worsens scenarios of health-related problems. The prevalence of SM has been increasing continuously in the past decades [13]. According to a study, SM practice with different OTC products and antibiotics has increased from $36.2 \%$ in 2019 to $60.4 \%$ in 2020 [14]. Moreover, the use of SMs for symptomatic treatment and based on the past experience of a patient is not a new phenomenon, this finding of ours is in line with the results of another study [15]. The majority of people were afraid to go out in the pandemic and more number of males were observed using medication with medical advice $[16,17]$. After the pandemic broke, a vast majority of population was left jobless. Bamgboye et al. determine self-education practice and factors affecting them, and had similar results as that of our study [18]. While SM due to common symptoms, respiratory tract infection, and due to fear was practiced only after the onset of pandemic, those practicing SM based on their past experience were doing so even before the lockdown and pandemic [19]. The WHO recommends the use of precautionary measures during the pandemic, however, it does not recommend SM for the symptoms of COVID-19 and related factors [20]. Despite this, frequent use of antibiotics was found among the studied population [21-22]. The use of medication for different symptoms were in accordance with the study.

\section{Conclusion}

The study aimed to find the prevalence of SM during COVID-19. Pharmacists and healthcare professionals are advised to counsel the population regarding the use of medication. A close collaboration is required at this stage to fight against COVID-19 and preventing the situation from worsening.

\section{Acknowledgements}

The authors acknowledge all supporting staff and faculty members who guided them throughout the research work.

\section{Ethical Considerations}

Verbal consent was taken from all responders prior to extracting data. 


\section{Competing Interests}

None.

\section{Availability of Data and Materials}

All relevant data and methodological details pertaining to this study are available to any interested researchers upon reasonable request to corresponding author.

\section{Funding}

None.

\section{References}

[1] Malik, M., Tahir, M. J., Jabbar, R., et al. (2020). Self-medication during Covid-19 pandemic: challenges and opportunities. Drugs \& Therapy Perspectives, vol. 36, no. 12 , pp. 565-567.

[2] Quispe-Cañari, J. F., Fidel-Rosales, E., Manrique, D., et al. (2021). Self-medication practices during the COVID-19 pandemic among the adult population in Peru: a cross-sectional survey. Saudi Pharmaceutical Journal, vol. 29, no. 1, pp. 1-11.

[3] Daniel, J. (2020). Education and the COVID-19 pandemic. Prospects, vol. 49, no. 1, pp. 91-96.

[4] Onchonga, D. (2020). A Google Trends study on the interest in self-medication during the 2019 novel coronavirus (COVID-19) disease pandemic. Saudi Pharmaceutical Journal: SPJ, vol. 28, no. 7, p. 903.

[5] Molento, M. B. (2020). COVID-19 and the rush for self-medication and self-dosing with ivermectin: a word of caution. One Health, vol. 10, 100148.

[6] Sadio, A. J., Gbeasor-Komlanvi, F. A., Konu, R. Y., et al. (2021). Assessment of selfmedication practices in the context of the COVID-19 outbreak in Togo. BMC Public Health, vol. 21, no. 1, pp. 1-9.

[7] Sahanic, S., Boehm, A., Pizzini, A., et al. (2020). Assessing self-medication for obstructive airway disease during COVID-19 using Google Trends. European Respiratory Journal, vol. 56, no. 5, 2002851.

[8] Watkins, J. (2020). Preventing a covid-19 pandemic. BMJ, vol. 368, m810. 
[9] Nicola, M., Alsafi, Z., Sohrabi, C., et al. (2020). The socio-economic implications of the coronavirus and COVID-19 pandemic: a review. International Journal of Surgery, vol. 78, pp. 185-193.

[10] Van Bavel, J. J., Baicker, K., Boggio, P. S., et al. (2020). Using social and behavioural science to support COVID-19 pandemic response. Nature human behaviour, 4(5), 460-471.

[11] Omer, S. B., Malani, P., and Del Rio, C. (2020). The COVID-19 pandemic in the US: a clinical update. JAMA, vol. 323, no. 18, pp. 1767-1768.

[12] Karbownik, M. S., Dobielska, M., Paul, E., et al. (2020). Health-, medication-and dietary supplement-related behaviors and beliefs relatively unchanged during the COVID-19 pandemic lockdown. Research in Social and Administrative Pharmacy.

[13] Ruiz, M. E. (2010). Risks of self-medication practices. Current Drug Safety, vol. 5, no. 4, pp. 315-323.

[14] Figueiras, A., Caamano, F., and Gestal-Otero, J. J. (2000). Sociodemographic factors related to self-medication in Spain. European Journal of Epidemiology, vol. 16, no. 1, pp. 19-26.

[15] Awad, A., Eltayeb, I., Matowe, L., et al. (2005). Self-medication with antibiotics and antimalarials in the community of Khartoum State, Sudan. Journal of Pharmacy and Pharmaceutical Sciences, vol. 8, no. 2, pp. 326-331.

[16] Afolabi, A. O. (2008). Factors influencing the pattern of self-medication in an adult Nigerian population. Annals of African medicine, vol. 7, no. 3, pp. 120-127.

[17] Mainous, A. G., Diaz, V. A., \& Carnemolla, M. (2008). Factors affecting Latino adults' use of antibiotics for self-medication. The Journal of the American Board of Family Medicine, vol. 21, no. 2, pp. 128-134.

[18] Selvaraj, K., Kumar, S. G., and Ramalingam, A. (2014). Prevalence of self-medication practices and its associated factors in Urban Puducherry, India. Perspectives in Clinical Research, vol. 5, no. 1, p. 32.

[19] Abasaeed, A., Vlcek, J., Abuelkhair, M., et al. (2009). Self-medication with antibiotics by the community of Abu Dhabi Emirate, United Arab Emirates. The Journal of Infection in Developing Countries, vol. 3, no. 7, pp. 491-497.

[20] Karimy, M., Rezaee-Momtaz, M., Tavousi, M., et al. (2019). Risk factors associated with self-medication among women in Iran. BMC Public Health, vol. 19, no. 1, pp. 1-7.

[21] Lukovic, J. A., Miletic, V., Pekmezovic, T., et al. (2014). Self-medication practices and risk factors for self-medication among medical students in Belgrade, Serbia. PloS ONE, vol. 9, no. 12, e114644. 
[22] Mansuri, F. M., Zalat, M. M., Khan, A. A., et al. (2020). Estimating the public response to mitigation measures and self-perceived behaviours towards the COVID19 pandemic. Journal of Taibah University Medical Sciences, vol. 15, no. 4, pp. 278283. 